D:INsurg|Vol. 24, No. 1, Jan. - Mar., 2020\Nsurg-5.Doc $\quad$ Fig. 1 Color $\quad$ (A) $\quad$ P. $21-27 \quad$ III

ORIGINAL ARTICLE

\title{
Microsurgical Resection of Intracranial Dermoid and Epidermoid Tumors (IDET)
}

\author{
AKRAMULLAH, MUSAWER KHAN, MUMTAZ ALI \\ Department of Neurosurgery, Lady Reading Hospital, Peshawar - Pakistan \\ DOI: $10.36552 /$ pjns.v24i1.413
}

\begin{abstract}
Objective: To Ascertain the outcome of microsurgical resection of intracranial dermoid and epidermoid tumors.

Materials and Methods: This prospective study was carried out in Neurosurgical Department, Lady Reading Hospital (LRH) Peshawar and followed for 3 years after microsurgical resection. All the patients with suspected intracranial Dermoid and epidermoid tumors (IDETs) on imaging study pre-operatively and later confirmed postoperatively (after histopathology) were enrolled. Patients having recurrent tumor, opting for nonsurgical management and those deem unfit for surgery were not included in the study.
\end{abstract}

Results: 27 patients were included in the study with 12 (44.4\%) males and 15 (56.6\%) female. Age of the patients rangefrom 11 to 58 years.Mean age was 38.6 years. Epidermoid tumors were 19 (70.3\%) in number and dermoid $8(29.7 \%)$ in number. The most common presentation was increased intracranial pressure (ICP) and cranial nerve deficit. The lesion was located in infratentorial location in 15 (56.6\%) patients, 12(44.4\%) were supratentorialy located. Gross total removal (GTR) was performed in 21 (77.8\%) patients, while in six patients (22.2\%) subtotal removal (STR) was attempted. 1 (3.7\%) patient died while 2 (7.4\%) patients had permanent morbidity post operatively, all other patients (89\%) improved. Recurrence occurred in $9.5 \%$ of GTR patients while in STR patients, $33.3 \%$ patients were noted with increase in residual tumor on neuroimaging.

Conclusion: Microsurgical resection with GTR is possible for most IDET and gives good results with minimal complications.

Keywords: Intracranial dermoid and epidermoid tumor, microsurgical resection of tumor, infratentorial tumor, supratentorial tumor.

\section{INTRODUCTION}

Intracranial dermoid and epidermoid tumors (IDET's) arise during embryogenesis as a result of ectopic epithelium being sequestered within the neural tube..$^{1-4}$ These tumors occur less frequently $(0.5-1 \%$ of all intracranial tumors). ${ }^{5,6}$ Iatrogenic occurrence of (IDET's) have been reported after procedures (lumbar puncture and percutaneous aspiration of subdural hematoma) which introduce epithelium into the nervous system. ${ }^{9}$ The most widely accepted theory is that during 3rd to 5th week of embryogenesis, sequestration abnormality of developing ectoderm into the closing neural tube results in IDET's formation. ${ }^{3,10,11}$ The evidence put forward in this regard is the frequent midline presentation and association of other congenital anomalies with dermoid cysts. ${ }^{4,12,13}$ Inclusion of mesodermal or mesenchymal cells is also hypothesized to be necessary with ectoderm cells, especially for laterally placed IDET's (cerebellopontine angle and Sylvian fissure. ${ }^{2,4}$ Lateral dermoid cysts may also represent displaced midline dermoid cysts. ${ }^{7}$

On CT scan epidermoids are hypodense (CSF like density).Punctate hyper densities in otherwise hypo dense lesion (dermoids are mostly fat filled capsules) signifies calcifications within the cyst. ${ }^{1,4,6,11-13}$ On MRI, epidermoids are hypo intense on T1WI and hyper intense on T2WI, while on diffusion weighted 
images it shows diffusion restriction. Dermoids show variable intensities, but mostly high intensity on $\mathrm{T} 1$ and low intensity on $\mathrm{T} 2$ images ${ }^{1,13,21}$ however, variable T2 intensities ranging from hypo intense signal to hyper intense signal attributed to variable densities of the fat component within the cyst is also reported5, 6.In contrast to epidermoid cysts, dermoid cyst rarely exhibits a restricted diffusion on diffusion weighted images, however, if thick content is present then dermoid may show restriction of diffusion., ${ }^{5,23}$ On contrast, studies epidermoid cyst usually appears homogenous non enchanting lesions while dermoid cyst present as heterogeneous non-enhancing lesion. ${ }^{4,5}$ Variable secretions and desquamation impart heterogeneity to dermoid cyst. ${ }^{6,11-13}$ With intravascular gadolinium contrast, peripheral enhancement may be observed. ${ }^{22}$ Radiological differentials of IDET's are usually teratoma, arachnoid cyst or cholesterol granuloma. $^{5,13,28}$ In contrast to arachnoid cyst epidermoid shows diffusion restriction. Dermoid have lesser diffusion restriction than epidermoid and cholesterol granuloma shows the greater inflammatory response on histology than dermoid cysts. ${ }^{5}$

IDET's are encapsulated by stratified squamous epithelium. ${ }^{2,5,6,11,28}$ Dermoid contains in addition to epithelium and its breakdown products (keratin and cholesterol)secretions from sebaceous glands, hair follicles, and even teeth, which usually explain why sometimes it is confused with teratoma. ${ }^{1,2,4,6,28}$ Teratoma must contain non cutaneous material and histopathology differentiates it from dermoid cyst.

There has been a tremendous improvement in microsurgical and cranial base techniques during the recent years. Technology has added immensely to the armamentarium of neurosurgeons and their surgical techniques. Endoscopic endonasal resection of IDET`s especially those situated in anterior skull base has been attempted with significantly lower risk of neurovascular injury due to better visualization through the endoscope. ${ }^{34}$ Endoscopic approach has also its inherent advantages over the microsurgical approach for anterior skull base lesions, like cosmetically more acceptable, retraction of brain parenchyma and neurovascular tissue is kept at a minimum and having shorter intra operative period and post op hospital stay. ${ }^{34}$ Skill and experience of the surgeon is the most important factor in determining the outcome after ideal instruments and technology availability is ensured. Nevertheless attaining endoscopic skills and selecting suitable patients for this approach is a challenging task as this is a relatively recent advancement. Despite all these advancements, IDET's management remains a formidable challenge to even experienced neurosurgeons because of their affinity for involvement of neurovascular tissues. A controversial debate still lingers on for many decades and still unresolved and the question such as should gross total removal (GTR) be attempted, which can result in neurovascular injury or should subtotal removal (STR) be performed instead?

Our goal of the current paper was to share our experience of managing IDET's in varying locations of intracranial cavity and elaborate our results, that may help the clinicians to compare and guide the management of these challenging tumors.

\section{MATERIALS AND METHODS}

\section{Study Design}

This prospective study was carried out in neurosurgery department, Lady Reading Hospital (LRH), Peshawar. Study duration was 3 years (May 2013 to May 2016). Each patient was followed for 3 years after microsurgery for intracranial dermoid epidermoid tumor (IDET).

\section{Inclusion Criteria}

All those patients were included having suspected intracranial dermoid or epidermoid tumor (IDET) on neuroimaging studies (hypointense on T1WI and hyperintense on T2 WI with no contrast enhancement, bright on diffusion weighted images and having postoperative histological confirmation of IDET. Patients of either gender, fit for surgery like having no systemic co morbidities (fit for anesthesia) and Karnofsky performance (KP) score 70 or above, were included in the study.

\section{Exclusion Criteria}

Those patients were excluded from the study who were not willing for surgery or unfit for surgery (significant anesthetic risk) and having the lower functional status (KP score less than 70). Also, patients having recurrent IDET or those having a postoperative histopathological diagnosis of other lesions than IDET were excluded.

\section{Data Collection}

On a Performa each patient's record in the form of demography, clinical outlook and radiological findings 
were enlisted pre operatively. Intra-operative appearance of the tumor, diagnosis after histopathology and follow up after removal were also documented.

Approval was taken from the ethical committee of MTI, Lady reading hospital, Peshawar. Preoperative complete history was taken from each patient and neurological examination was performed. Informed consent was signed from each patient or relevant attendant pre operatively. Anesthesia fitness was ensured and necessary investigations (MRI brain with and without contrast and diffusion weighted images) were completed before surgery. Preoperative arrangement of donor blood was ensured where required.

\section{Follow-up}

Postoperative MRI with and without contrast were obtained on $3^{\text {rd }}$ and $6^{\text {th }}$ months after surgery and every 6 months afterwards for the next 2 and half years.

\section{Microsurgical Technique}

The microsurgical approach to IDET depends on tumor location and growth pattern. Depending on tumor location specific surgical approaches were used by our surgical team: (i) Suboccipital retromastoid approach (40.7\%)was utilized for tumors in the CPA area (ii) Sellar and arasellar lesions were accessed by a pterional craniotomy with wide splitting of the Sylvian cistern arachnoid membrane $(14.8 \% \%$ ), (iii) Cerebellar IDET were excised via midline suboccipital approach (14.8\%); (iv) frontal and temporal lesions (29.6\%) were removed via a frontal craniotomy and a temporal craniotomy, respectively. Since, sub occipital approach was mainly used for tumor excision in our study, we will describe our surgical techniques in managing 11 IDET`s located in the CPA.

\section{Position and Incision}

We used the same standard microsurgery technique for each CPA tumor, incorporating standard microsurgery principles. Patient positioning and dissection: After giving General anesthesia intubation was performed, the patient was put in lateral position.Hair shaved in line of surgical incision, local anesthesia with adrenaline administered and the area than prepared with antiseptic solution and draped afterwards. $5 \mathrm{~mm}$ behind the mastoid notch a straight skin incision was given which extended $6 \mathrm{~cm}$ superiorly and $5 \mathrm{~cm}$ inferiorly to the notch. In the line of incision galea and periosteum were incised as well.Bipolar coagulation and bone wax used for hemostasis during the dissection.

\section{Craniectomy}

Suboccipital bone was thinned out with the help of a drill. Using leksellrongeur, craniectomy was performed extending from the inferior and lateral borders of the transverse and sigmoid sinus, respectively to $3-4 \mathrm{~cm}$ posteroinferiorly. The operating microscope was introduced in the surgical field.

\section{Opening the Dura}

A curvilinear incision was given in the dura and its edges everted with 4/0 silk suture. CSF was drained from cisterna magna.

\section{Tumor Exposure}

Tumor was located and retractors were gently placed helping in retracting cerebellum upward and improve the tumor exposure. The arachnoid membrane covering the tumor was incised and tumor is reached.

\section{Tumor Removal}

Tumor was debulked from within and piecemeal removal was favored to avoid stretching critical neurovascular tissue located there. Preserving and following the arachnoid plane was critical to gross total removal of the lesion. The tumor was then mobilized and dissected away from lower cranial nerves, critical arterial branches and feeders and brainstem. As the surgery advanced and tumor removal followed, an additional room was created, which not only added to the safety of vital neuromuscular tissue but also eased further dissection. After the surgeon was satisfied about the safe maximal resection thorough irrigation, the suction was performed. Following standard operative nuances GTR was achieved in majority cases, but in few cases it was sometimes necessary to leave behind tumor fragments to avoid neuromuscular insults.

Cyst content was prohibited to come in contact with the subarachnoid space by using irrigationsuction and cotton petties in the surgical field. Before closing the dura final view of the surgical field was taken to ensure removal of any residuals and to ensure a dry field.Bone wax was then used over the edges of themastoid craniectomy wound to avoid postoperative 
CSF leakage. Usually the patient is shifted to ICU for at least 1 day and when remain more stable than shifting towards for further management

\section{RESULTS}

\section{Age Incidence}

We included 27 patients in our study. Age was ranging from 11 to 58 years with a mean of 38.6 years.

\section{Gender Distribution}

Table 1 shows the gender specifics, histological diagnosis, location and clinical presentation of the tumors.

\section{Clinical Presentation}

The presentation and clinical findings were consistent with the tumor location.Cranial nerves involved were mainly trigeminal and vestibulocochlear in $\mathrm{CP}$ angle and optic nerve in parasellar tumors. Infra tentorial tumors mostly presented with signs of increased intracranial pressure (ICP), cranial nerves deficit and cerebellar signs while supra tentorial tumors presented with seizures, visual deficits and limbs weakness. Frequency of each sign is given in the table below (Table 1). In 3 patients with posterior fossa IDET, VP

Table 1: Distribution of Parameters.

\begin{tabular}{|c|c|}
\hline Gender & Number (Percentage) \\
\hline Male & $12(44.4 \%)$ \\
\hline Female & $15(55.6 \%)$ \\
\hline Histopathology of Tumor & $19(70.3 \%)$ \\
\hline Epidermoid tumor & $8(29.7 \%)$ \\
\hline Dermoid tumor & \\
\hline Location & $11(40.7 \%)$ \\
\hline Cerebellopontine Angle & $5(18.5 \%)$ \\
\hline Temporal Region & $4(14.8 \%)$ \\
\hline Parasellar Area & $4(14.8 \%)$ \\
\hline Cerebellar Hemisphere & $3(11.1 \%)$ \\
\hline Frontal Region & \\
\hline Presentation & $9(33.3 \%)$ \\
\hline Increased Intracranial Pressure & $9(33.3 \%)$ \\
\hline Cranial Nerves Deficit & $6(22.2 \%)$ \\
\hline Cerebellar Signs & $4(14.8 \%)$ \\
\hline Seizures & $4(14.8 \%)$ \\
\hline Visual Deficits & $2(7.4 \%)$ \\
\hline Limb Weakness & \\
\hline & \\
\hline
\end{tabular}

shunt was placed for hydrocephalus before microsurgery.

Microsurgery was performed in all 27 patients. Table 2 provides the data about the extent of tumor resection, outcome and follow up results.Gross total removal and subtotal removal (STR) were confirmed by surgeon's impression during surgery and postoperative neuroimaging. All the patients were kept in the intensive care unit (ICU) for at least 24 hours after surgery, butsomepatients required a prolong ICU stay due to transient complications.Mean length of stay in the ICU was $1.70 \pm 1.14$. Each patient was kept in neurosurgery ward for at least 2 days after stabilization in ICU. 4 patients had transient fascial nerve palsy and in 2 others, there were transient swallowing difficulties after microsurgery which resolved with conservative management. 3 patients had postoperative cerebrospinal fluid (CSF) leak, out of which 2 resolved with conservative management and 1 patient was re operated and dural graft was placed at leak site, after which it resolved. 2 patients required CSF diversion (VP shunt) post operatively for posterior fossa IDET. 2 patients had an early postoperative tumor bed bleeds, which required re exploration of tumor bed and hematoma evacuation with the securing of hemostasis. 1 patient improved while other expired after re exploration.

Apart from single (3.7\%) mortality and two (7.4\%) patients having permanent hearing loss (in $\mathrm{CP}$ angle IDET) all other patients (89\%) improved symptomatically after surgery. Each patient was followed for 3 years after microsurgery with clinical evaluation and neuroimaging at $3^{\text {rd }}$ and $6^{\text {th }}$ month post operatively and 6 monthly afterwards for 2 and half years.

Table 2: Distribution of Parameters.

\begin{tabular}{|c|c|}
\hline Completeness of Removal & Number (Percentage) \\
\hline Gross total removal(GTR) & $21(77.8 \%)$ \\
\hline Subtotal removal(STR) & $6(22.2 \%)$ \\
\hline Outcome & $1(3.7 \%)$ \\
\hline Mortality & $2(7.4 \%)$ \\
\hline Permanent Morbidity & $24(88.9 \%)$ \\
\hline Improvement & \\
\hline Follow-up & $2(9.5 \%)$ \\
\hline Recurrence in GTR & $2(33.3 \%)$ \\
\hline Increase size in STR & \\
\hline
\end{tabular}




\section{Frequency of Dermoid vs. Epidermoid}

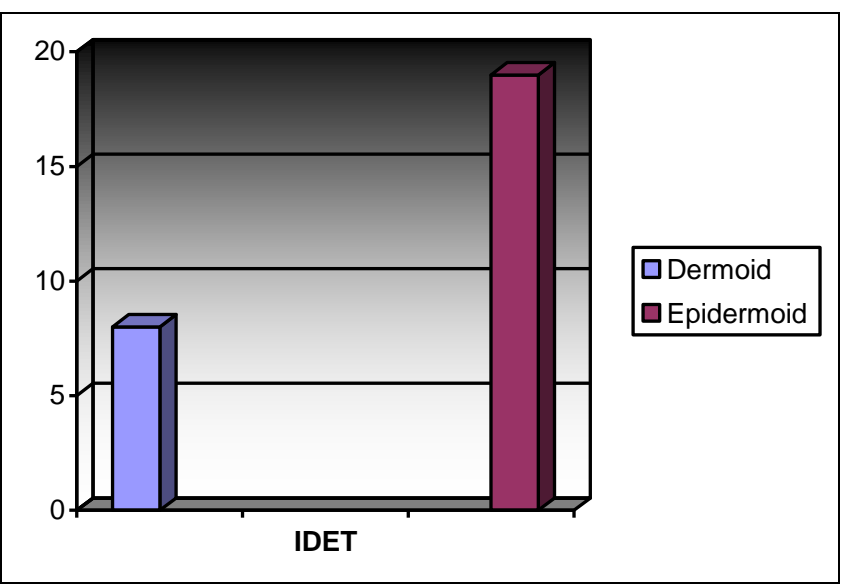

Fig. 1: Repreentation of freuqency of dermoid vs epidermoid.

\section{DISCUSSION}

IDET's are congenital lesions with no gender predilection. ${ }^{1,6,8}$ We found that the distribution of these tumors does not favor a specific gender, which is $55.4 \%$ for female and $44.6 \%$ for male gender in our study. Age of presentation of these tumors is usually comparatively younger age group for dermoid tumors, while epidermoid usually present in 3rd to 5th decade of life until it achieves significant growth to cause mass effect or spontaneous rupture. ${ }^{2,5,13,20}$ In our study IDET occur in age range of 11 to 58 years and epidermoid were slightly more prevalent in middle age group while dermoid in younger age group.

In our study, we found that about $55.5 \%$ of IDET were found in an infratentorial cranial compartment with mostly in cerebellopontine (CPA) location while supratentorial IDET account for $44.5 \%$. This finding is consistent with many other studies conducted on IDET. Liu and colleagues find thatwhile epidermoid are common in peripheral locations, dermoid cysts are mostly found in the midline location of neuraxis. ${ }^{24}$ Prior studies supported infratentorial location around cerebellar vermis and 4th ventricle as most common, but recent literature shows increase in supratentorial occurrence of dermoids6, 25. Supratentorial cysts are most common at seller, temporal and frontobasal locations and less common in cavernous sinus 26 . IDET are thought to be equally distributed among the three cranial fossae, but certain locations show more predilection than others, as in CPA they usually account for 7-9\% of all tumors in this location. ${ }^{7,11,32}$

Presentation of IDET, like any other intracranial tumor mostly depends on its location where it causes focal deficits (involving neurovascular or brain tissue) or global effects (mostly increased intracranial pressure). As most of the tumors were found infratentorial in origin so increased intracranial pressure and cranial nerve deficit were the most common presentation (33.3\% each) in our study. Many studies support this pattern of presentation for occurrence of IDET where Signs and symptoms depend upon location of cyst but most present with symptoms of increased ICP, headache and seizures. ${ }^{4,6,11-13}$ Cranial neuropathies are common with involvement of the extra ocular muscles and visual impairment, fascial nerve and trigeminal nerve involvement. Ruptured IDET usually presents with acute or recurrent meningitis, asymptomatic patients are usually diagnosed during routine imaging for head trauma. ${ }^{1,15-19}$ Acute headache or meningitis also occurs due to traumatic rupture of dermoid and epidermoidcysts. ${ }^{17}$

Again, the surgical approach to these tumors is guided by its location. For CPA tumors, we used the retrosigmoid sub occipital craniectomy approach, while for cerebellar one we used the posterior midline craniotomy approach for parasellar lesions, pterionalcraniotomy was performed and frontal and temporal craniotomies were utilized for frontal and temporal IDET respectively. Gross total removal (GTR) or subtotal removal (STR), both options are supported by neurosurgeons. Each of these two strategies has its inherent pros and cons.We, in our study stride for GTR, where possible and kept the safety of neuronal and neurovascular tissue our top priority. STR was performed in $22.2 \%$ patients where complete resection was felt risky. Complete surgical resection is not possible if the capsule is adherent to neuromuscular or vital structures (brainstem). Gross total resection is associated with higher morbidity, while subtotal resection is associated with lesser chances of recurrence, ${ }^{7}$ so the goal is to remove maximal possible tumor without compromising important structures. ${ }^{12}$ Location of cyst guides the surgical approach. Middle fossa lesions are mostly removed via pterional craniotomy ${ }^{4,11,28}$ posterior fossa lesions via sub occipital ${ }^{1,13}$ and $\mathrm{CP}$ angle tumors via retrosigmoid approach. ${ }^{10,29}$

About $89 \%$ of patients had improvement of symptoms to their satisfaction level and improved quality of life. We had encountered single (3.7\%) mortality and $2(7.4 \%)$ permanent morbidities in our study. Some of our patients had transient cranial 
nerves deficit or short term complications post operatively, but those were temporary and managed accordingly. Earlier, there used to be high mortality rates during surgeries for IDET, but due to improvement in surgical procedures and advancement in technology, it has improved dramatically. In pre microscopic era, operative mortality was quoted from $20 \%$ to $57 \% .^{33}$ Yasargil and colleagues reported mortality rate of $5 \%$ in their study. They operated 43 patients with IDETs in which they cited meningitis and transient lower cranial palsies as the most prevalent complications after surgery. ${ }^{30}$

Since IDET are slow growing benign tumors. They show linear growth and, afterthe GTR recurrence rate is low in these tumors. With STR, there is a greater chance of growth of the residual tumor and need for re operation. ${ }^{6}$ Greater chances of recurrence in deeply situated IDET's after surgery is due to residual tumor left due to improper visualization during surgery. In our follow up period of 3 years, 9.6\% tumors recurred after GTR, while $33.3 \%$ tumor showed an increase in residual tumor size.

\section{CONCLUSION}

Controversy still prevails in surgical management of IDET's, but our study and literature points to GTR as the strategy of choice, using meticulous microsurgery techniques to obtain the cure of the patient. GTR was performed in $77.8 \%$ of our patients with lesser complication rates, but it is not always possible to achieve, asthe location of the tumor near critical neurovascular tissue prevents complete excision of the tumor. As improving the patient's quality of life is sine qua non for a successful management plan, preservation of vital neurovascular structures should precede any decision about gross total or subtotal tumor removal.

\section{REFERENCES}

1. Li ZJ, Miao YX, Sun $P$, et al. Unusual CT hyperattenuatingdermoid cyst of cerebellum: a new case report and literature review. Cerebellum, 2011; 10 (03): 536-539.

2. Linkov G, Kanev PM, Isaacson G. Conservative management of typical pediatric postauriculardermoid cysts. Int J Pediatr Otorhinolaryngol. 2015; 79 (11): 1810-1813.

3. Zimny A, Zińska L, Bladowska J, Neska-Matuszewska M, Sasiadek M.Intracranial lesions with high signal intensity on T1-weighted MR images - review of pathologies. Pol J Radiol. 2013; 78 (04): 36-46.
4. Schneider UC, Koch A, Stenzel W, Thomale UW. Intracranial, supra-tentorial dermoid cysts in paediatric patients-two cases and areview of the literature. Childs Nerv Syst. 2012; 28 (02): 185-190.

5. Osborn AG, Preece MT. Intracranial cysts: radiologicpathologiccorrelation and imaging approach. Radiology, 2006; 239 (03): 650-664.

6. Akdemir G, Daglioglu E, Ergüngör MF. Dermoid lesion of the cavernous sinus: case report and review of the literature. Neurosurg Rev. 2004; 27 (04): 294-298.

7. Garces J, Mathkour M, Beard B, Sulaiman OA, Ware ML. Insular and sylvian fissure dermoid cyst with giant cell reactivity: case reportand review of literature. World Neurosurg. 2016; 93: 491.e1-491.e5.

8. Vega RA, Hidlay DT, Tye GW, Fuller CE, Rhodes JL. Intradiploic dermoid cyst of the lateral frontotemporal skull: case report and review of the literature. Pediatr Neurosurg. 2013; 49 (04): 232-235.

9. Niederhagen B, Reich RH, Zentner J. Temporal dermoid with intracranial extension: report of a case. J Oral Maxillofac Surg. 1998; 56 (11): 1352-1354.

10. Plans G, Aparicio A, Majós C. Intracranial dermoid cyst rupture with subarachnoid and intraventricular fat dissemination. Neurology, 2006; 66 (12): 1937.

11. El-Bahy K, Kotb A, Galal A, El-Hakim A. Ruptured intracranial dermoid cysts. Acta Neurochir (Wien), 2006; 148 (04): 457-462.

12. Turgut M. Klippel-Feil syndrome in association with posteriorfossa dermoid tumour. Acta Neurochir (Wien), 2009; 151 (03): 269-276.

13. Sanchez-Mejia RO, Limbo M, Tihan T, Galvez MG, Woodward MV, Gupta N. Intracranial dermoid cyst mimicking hemorrhage. Case report and review of the literature. J Neurosurg. 2006; 105 (04): 311-314.

14. Ecker RD, Atkinson JL, Nichols DA. Delayed ischemic deficit after resection of a large intracranial dermoid: case report and review of the literature. Neurosurgery, 2003; 52 (03): 706-710, Discussion, 709-710.

15. Jyoti Das C, Tahir M, Debnath J, Shyam Pangtey G. Ruptured intracranial dermoid. BMJ Case Rep. 2009; 2009: bcr2006109835b.

16. Kim IY, Jung S, Jung TY, Kang SS, Kim TS. Traumatic rupture ofan intracranial dermoid cyst. J Clin Neurosci. 2008; 15 (04): 469-471.

17. Park SK, Cho KG. Recurrent intracranial dermoid cyst after subtotal removal of traumatic rupture. Clin Neurol Neurosurg. 2012; 114 (04): 421-424.

18. Yaldiz C, Duransoy YK, Mete M, Simsek T, Isisag A, Selçuki M. Dermoid cyst rupture presenting as subarachnoid hemorrhage: report of a rare case. Neurosurg Q. 2015; 25 (04): 461-464.

19. Luan Y, Wang H, Zhong Y, Bian X, Luo Y, Ge P. Traumatic hemorrhage within a cerebellar dermoid cyst. Int J Med Sci. 2012; 9 (01): 11-13.

20. Bellet JS. Developmental anomalies of the skin. Semin Perinatol. 2013; 37 (01): 20-25. 
21. rakcioglu B, Halatsch $\mathrm{ME}$, Fortunati $\mathrm{M}$, Unterberg A, Yonekawa Y. Intracranial dermoid cysts: variations of radiological and clinical features. Acta Neurochir (Wien), 2008; 150 (12): 1227-1234, Discussion, 1234.

22. Ageshio $\mathrm{N}$, Shimono $\mathrm{T}$, Goto $\mathrm{T}$, et al. Imaging appearance of petrousapex dermoid cysts containing little or no fat. JPN J Radiol. 2013; 31 (02): 133-137.

23. Aksoy FG, Aksoy OG, Gomori JM. Klippel-Feil syndrome in association with posterior fossa suboccipital dermoid cyst. Eur Radiol. 2001; 11 (01): 142-144.

24. Liu JK, Gottfried ON, Salzman KL, Schmidt RH, Couldwell WT. Ruptured intracranial dermoid cysts: clinical, radiographic, and surgical features. Neurosurgery, 2008; 62 (02): 377-384, Discussion, 384.

25. Johnson DG, Stemper SJ, Withers TK. Ruptured "giant" supratentorial dermoid cyst. J Clin Neurosci. 2005; 12 (02): 198-201.

26. Caldarelli M, Colosimo C, Di Rocco C. Intra-axial dermoid/epidermoid tumors of the brainstem in children. Surg Neurol. 2001; 56 (02): 97-105.

27 van Calenbergh F, Demaerel P, Sciot R, vanGool S. Long-term survival in a child with a brain stem dermoid cyst. Surg Neurol. 2005; 63 (03): 261-263, Discussion, 263-264.

28. Vega RA, Hidlay DT, Tye GW, Fuller CE, Rhodes JL.
Intradiploic dermoid cyst of the lateral frontotemporal skull: case report and review of the literature. Pediatr Neurosurg. 2013; 49 (04): 232-235.

29. Kang MG, Kim KJ, Seok JI, Lee DK. Intracranial dermoid cyst rupture with midbrain and thalamic infarction. Neurology, 2009; 72 (08): 769.

30. Yasargil MG, Abernathey CD, Sarioglu AÇ. Microneurosurgical treatment of intracranial dermoid and epidermoid tumors. Neurosurgery, 1989; 24 (04): 561-567.

31. Ahmed I, Kurtis AI, Vachhrajani S, Dirks PB, Drake JM, Rutka JT. Neurosurgical management of intracranial epidermoid tumors in children. J Neurosurg Pediatr. 2009; 40: 91-6.

32. Talacchi A, Sala F, Alessandrini F, Turazzi S, Bricolo A. Assessment and surgical management of posterior fossa epidermoid tumors: Report of 28 cases. Neurosurgery, 1998; 42: 242-52.

33. Lynch JC, Aversa A, Pereira C, Nogueira J, Goncalves M, Lopes H. Surgical strategy for intracranial dermoid and epidermoid tumors: An experience with 33 Patients. Surg Neurol Int. 2014; 5: 163.

34. Vaz-Guimaraes F, Koutourousiou M, Almeida JRd, Tyler-Kabara EC, Fernandez-Miranda JC, Wang EW, et al. Endoscopic endonasal surgery for epidermoid and dermoid cysts: a 10-year experience, 2018; 130 (2): 368 .

\section{Additional Information}

Disclosures: Authors report no conflict of interest.

Ethical Review Board Approval: The study was conformed to the ethicalreview board requirements.

Human Subjects: Consent was obtained by all patients/participants in this study.

Conflicts of Interest:

In compliance with the ICMJE uniform disclosure form, all authors declare the following:

Financial Relationships: All authors have declared that they have no financial relationships at present or within the previous three years with any organizations that might have an interest in the submitted work.

Other Relationships: All authors have declared that there are no other relationships or activities that could appear to have influenced the submitted work.

Address for Correspondence: Dr. Akramullah Prime Teaching Hospital, Peshawar Medical College. Email:-akramullah@hotmail.com Contact:03339415678

\begin{tabular}{|c|c|c|c|}
\hline \multicolumn{4}{|c|}{ AUTHORSHIP AND CONTRIBUTION DECLARATION } \\
\hline Sr.\# & Author's Full Name & Intellectual/Contribution to Paper in Terms of: & Signature by the \\
\hline 1. & Akramullah & 1. Proposed topics and Basic Study Design, methodology. & \\
\hline 2. & Musawer Khan & 2. Data collection and calculations & \\
\hline 3. & Mumtaz Ali & 3. Analysis of data \&Paper writing. & Now \\
\hline
\end{tabular}

Date of Submission: 02-02-2020

Date of Print: 31-03-2020

Date of Revision: 01-03-2020

Date of Online Publishing: 31-03-2020 